\title{
Evaluación de la calidad del agua en restaurantes de la ciudad de San José de Cúcuta, de diferentes estratos, para contribuir con la seguridad alimentaria
}

\author{
Evaluation of water quality in restaurants of the city of San José Cúcuta, from different strata, \\ to contribute to food security
}

\begin{abstract}
Martínez Karen¹, Caballero Raquel ${ }^{2}$, Díaz Enrique ${ }^{2}$, Pérez Katherine ${ }^{2}$, Suarez Stephanie ${ }^{2}$
${ }^{1}$ Universidad de Santander, UDES, Sede Cúcuta, Facultad de Salud, Programa de Bacteriología y Laboratorio Clínico, Semillero de investigación Orugas

${ }^{2}$ Estudiantes Semillero de investigación Orugas
\end{abstract}

Recibido 25 Abril 2015; aceptado de 28 Mayo 2015

\section{RESUMEN}

Teniendo en cuenta la utilidad del agua potable dentro de restaurantes, la calidad es relevante, dado su uso en lavado de manos, preparación de alimentos, limpieza y desinfección de equipos, superficies, frutas y verduras. De acuerdo a esto, el objetivo del presente estudio fue evaluar de la calidad del agua de restaurantes de la ciudad de San José de Cúcuta, para contribuir con la seguridad alimentaria. La población estuvo conformada por 40 restaurantes pertenecientes a diferentes estratos de la ciudad de Cúcuta. Se llevó a cabo el diagnóstico visual de los tanques de almacenamiento del agua y se realizaron 3 muestreos en cada restaurante en dos puntos diferentes: tanque de almacenamiento y grifo, para un total de 141 muestras analizadas. Para el procesamiento de las muestras se empleó el método de filtración por membrana, contando con el uso de medios de cultivo: agar Plate count para conteo de aerobios mesofilos y agar Chromocult para coliformes totales y fecales, con el uso de membranas de $0.45 \mathrm{~mm}$, e incubación a $37^{\circ} \mathrm{C}$. Se halló que el $60 \%$ cumplen el con la normatividad vigente, la resolución 2115 de 2007, el 40\% de ellos no cumple con dicha normativa; el incumplimiento obedeció a parámetros microbiológicos en el $40 \%$ de las muestras, hallando no cumplimiento en aerobios mesofilos, y coliformes totales, el $100 \%$ de las muestras no presentaron coliformes fecales. Se establecieron planes de mejora, dado que se evidenció falta de limpieza y desinfección en tanques de almacenamiento.

*Autor a quien debe dirigirse la correspondencia. E-mail: karitomartinez.1@gmail.com
Palabras clave: agua, calidad, contaminación, seguridad alimentaria, tanques de almacenamiento. 


\begin{abstract}
Considering the usefulness of drinking water in restaurants, quality is important, given their use in hand washing, food preparation, cleaning and disinfection of equipment, surfaces, fruits and vegetables. Accordingly, the objective was to contribute to the formation of seed research, by assessing the water quality of restaurants in the city of San Jose de Cucuta, to contribute to food security. The population consisted of 40 restaurants belonging to different strata of the city of Cucuta. Carried out the visual diagnosis of water storage tanks and 3 samples in each restaurant were conducted at two different points: storage tank and tap, for a total of 141 samples analyzed. For sample processing method used for membrane filtration, with the use of culture media: agar Plate count to count aerobic mesophilic bacteria and agar Chromocult for total and fecal coliforms, with the use of membranes of $0.45 \mathrm{~mm}$, and incubation at $37^{\circ} \mathrm{C}$. It was found that $60 \%$ meet the current regulations with the resolution 2115 of 2007, 40\% of them do not comply with such regulations; the failure was due to microbiological parameters in $40 \%$ of the samples, finding no fulfillment in aerobic mesophilic bacteria and total coliforms, $100 \%$ of the samples presented fecal coliform. improvement plans were established, since lack of cleaning and disinfection was demonstrated in storage tanks.
\end{abstract}

\title{
INTRODUCCIÓN
}

Keywords: water quality, pollution, food safety, storage tanks

Las enfermedades diarreicas por toxoinfecciones causan a nivel mundial alrededor de 1,8 millones de muertes, el $90 \%$ de las cuales corresponden a niños menores de cinco años de países en vías de desarrollo, porque el $88 \%$ de tales enfermedades diarreicas son producto de un abastecimiento de agua insalubre, así como de un saneamiento ambiental y una higiene sanitaria deficientes (Moya Raquel et al., 2013). Los brotes de enfermedades infecciosas transmitidas por el consumo de agua contaminada siguen siendo grave amenaza de salud en todo el mundo, a pesar de que el agua potable es uno de los recursos más estrechamente vigilados y estrictamente regulados, este fenómeno no solo sucede en los países en desarrollo sino también es amenaza en los países desarrollados. La presencia de crecimiento bacteriano en agua potable puede multiplicar los efectos adversos en los sistemas de distribución de una manera incontrolable. Muchos investigadores, han observado que el almacenamiento de agua en el hogar conduce a un deterioro de la calidad del agua debido a su contaminación. Incluso si las familias tienen una fuente de agua limpia para beber, el agua puede contaminarse en el hogar debido a la falta de higiene y de prácticas de mantenimiento a filtros y desinfección de contenedores de agua. El agua potable, es un servicio básico en cualquier parte del mundo, pero las comunidades ubicadas en los alrededores de las ciudades, no son atendidas de igual manera que el área central de las mismas. Cada sistema de gobierno se encarga de distribuir el agua a sus comunidades. Sin embargo, no existe un monitoreo de la calidad del agua, no se lleva un control microbiológico sistemático, necesario para asegurar la potabilidad del agua. (Alba José de Jesús et al., 2013). El acceso al agua potable y a condiciones adecuadas de saneamiento es esencial para la salud, un derecho humano básico y un componente de la política para la protección de la salud. Teniendo en cuenta que el abastecimiento de agua debe 
garantizar tanto la cantidad como la calidad del agua que llega al consumidor, las últimas tendencias en el sector de agua potable están orientadas al desarrollo y aplicación de metodologías para la identificación, evaluación y control de los riesgos que se presentan en un sistema de abastecimiento, así como a la formulación de programas de vigilancia y control de la calidad de la misma (Montoya, Carolina et al., 2009). Por la importancia que representa el agua en el interior de restaurantes, y de acuerdo a los diversos usos que se da de esta, se planteó como propósito, evaluar la calidad del agua en restaurantes de la ciudad de San José de Cúcuta, de diferentes estratos, para contribuir con la seguridad alimentaria.

\section{MATERIALES Y MÉTODOS}

\section{Muestreo}

Se seleccionaron 40 restaurantes de diferentes estratos de la ciudad de Cúcuta, desde el Malecom, terminal de transportes, zona centro y zonas de comunidades de barrios periféricos, en restaurantes de alimentación escolar. Se realizaron 3 muestreos que incluyeron toma de muestra de tanques, y grifos, tan solo en el $55 \%$ de los lugares se logró tomar muestras en los tanques de almacenamiento en el primer muestreo, y en un $75 \%$ se tomaron en los grifos.

\section{Métodos}

Se dividieron en dos fases: revisión de la situación de almacenamiento del agua en los restaurantes, revisión de las condiciones de los grifos y realización de preguntas sobre limpieza y desinfección de tanques de almacenamiento.

Se tuvo en cuenta para la toma el uso de bolsas whirlpack con pastillas de tiosulfato de sodio, cavas con pilas de hielo, alcohol, una vez tomadas las muestras fueron transportadas a $4^{\circ} \mathrm{C}$, a fin de evitar la alteración de carga microbiana.

Las muestras fueron procesadas en el Laboratorio de Bioquímica de la Universidad de Santander con sede en Cúcuta, la técnica empleada fue: filtración por membrana.

\section{Procesamiento de la muestras}

El método empleado fue la técnica de filtración por membrana, donde se agitan las muestras y se filtran $50 \mathrm{ml}$ de cada una, haciéndola pasar por la membrana de nitrocelulosa, la cual, se ubicaba sobre el agar Plate count y del agar chromocuth, e incubados a $37^{\circ} \mathrm{C}$, durante 24 a 48 horas. Como control se tuvo en cuenta muestras de agua potable de un tanque limpio y protegido para tener como referencia para correlacionar con los resultados obtenidos a partir de las muestras de los diferentes restaurantes. Se tuvieron en cuenta controles para los medios de cultivo empleados. Para el análisis de resultados se tuvo referencia la normatividad Colombiana, representada en la resolución 2115 de 2007, donde el máximo de aerobios mesófilos debe ser de 100 ufc/100 ml, y para coliformes totales y fecales, debe ser 0 ufc/ $100 \mathrm{ml}$ analizados. Se llevaron a cabo 3 muestreos en los mismos puntos, durante el mes de noviembre de 2014.

\section{Socialización de resultados}

Los resultados obtenidos fueron socializados en cada uno de los restaurantes participantes, donde se incluyó la entrega de cada reporte por muestreo, además de una estadística y explicación de los resultados, así mismo se entregó en cada sitio, un plan de mejoras con la finalidad de que este sea puesto en marcha con el objetivo de mejorar y mantener altos niveles de calidad del agua. 


\section{RESULTADOS Y DISCUSIÓN}

Los resultados de los análisis microbiológicos realizados al agua se encuentran en las tablas 1,2 y 3 , de acuerdo a los tres muestreos realizados.

Tabla 1

Resultados primera toma de muestra, tanques de almacenamiento: Noviembre 3 y 4 de 2014

\begin{tabular}{|c|c|c|}
\hline \multirow[b]{2}{*}{$\begin{array}{l}\text { Código } \\
\text { restaurante }\end{array}$} & \multicolumn{2}{|c|}{ Ufc/100 ml } \\
\hline & $\begin{array}{l}\text { Aerobios } \\
\text { mesófilos }\end{array}$ & $\begin{array}{c}\text { Coliformes } \\
\text { totales }\end{array}$ \\
\hline 1 & 0 & 0 \\
\hline 2 & 10 & 0 \\
\hline 3 & 15 & 0 \\
\hline 4 & 25 & 3 \\
\hline 5 & 80 & 1 \\
\hline 6 & 60 & 0 \\
\hline 7 & 20 & 0 \\
\hline 8 & 35 & 2 \\
\hline 9 & 75 & 0 \\
\hline 10 & 87 & 0 \\
\hline 11 & 36 & 0 \\
\hline 12 & 64 & 0 \\
\hline 13 & 78 & 0 \\
\hline 14 & 56 & 2 \\
\hline 15 & 84 & 0 \\
\hline 16 & 89 & 6 \\
\hline 17 & 76 & 3 \\
\hline 18 & 65 & 2 \\
\hline 19 & 35 & 0 \\
\hline 20 & 21 & 0 \\
\hline
\end{tabular}

Fuente: autores

Normatividad colombiana para aerobios mesofilos máximo $100 \mathrm{ufc} / 100 \mathrm{ml}$, para coliformes totales 0 ufc/ $100 \mathrm{ml}$, esto de acuerdo a la resolución 2115 de 2007.

De estos primeros 20 recuentos, se estableció que no hay cumplimiento para 7 restaurantes ya que excedían el parámetro de coliformes, donde este tiene un permisible de $0 \mathrm{ufc} / 100 \mathrm{ml}$ y se hallaron de 2 hasta 6 ufc en restaurantes diferentes. Es de aclarar que coliformes fecales no se hallaron en ninguna de las muestras analizadas.

De acuerdo a la tabla 2, se comprobó que no hay cumplimiento para 30 restaurantes ya que excedían el parámetro de coliformes, teniendo en cuenta los 3 muestreos, donde este tiene un permisible de 0 ufc/ $100 \mathrm{ml}$. Es de aclarar que coliformes fecales no se hallaron en ninguna de las muestras analizadas.
Tabla 2

Resultados primera, segunda y tercera toma en grifos de restaurantes

\begin{tabular}{|c|c|c|c|c|c|c|}
\hline \multirow[t]{3}{*}{$\#$} & \multicolumn{2}{|c|}{$\begin{array}{c}\text { TOMA } 1 \\
\text { Noviembre } 3 \text { y } 4 \\
\text { De } 2014\end{array}$} & \multicolumn{2}{|c|}{$\begin{array}{c}\text { TOMA 2 } \\
\text { Noviembre } 11 \text { y } 13 \\
\text { de } 2014\end{array}$} & \multicolumn{2}{|c|}{$\begin{array}{c}\text { TOMA } 3 \\
\text { Noviembre } 17 \text { y } 18 \\
\text { de } 2014\end{array}$} \\
\hline & & & Grifo & $100 \mathrm{ml}$ & & \\
\hline & AM & CT & AM & CT & AM & CT \\
\hline 1 & 50 & 1 & 15 & 0 & 16 & 0 \\
\hline 2 & 54 & 0 & 27 & 0 & 29 & 0 \\
\hline 3 & 100 & 15 & 110 & 7 & 111 & 7 \\
\hline 4 & 28 & 3 & 15 & 3 & 76 & 3 \\
\hline 5 & 85 & 1 & 90 & 2 & 91 & 2 \\
\hline 6 & 67 & 0 & 70 & 0 & 76 & 0 \\
\hline 7 & 20 & 0 & 25 & 0 & 27 & 0 \\
\hline 8 & 86 & 1 & 77 & 1 & 79 & 2 \\
\hline 9 & 80 & 0 & 67 & 0 & 70 & 0 \\
\hline 10 & 91 & 0 & 82 & 0 & 86 & 0 \\
\hline 11 & 38 & 0 & 20 & 0 & 27 & 0 \\
\hline 12 & 68 & 0 & 62 & 0 & 68 & 0 \\
\hline 13 & 79 & 0 & 13 & 0 & 17 & 0 \\
\hline 14 & 64 & 2 & 77 & 3 & 79 & 3 \\
\hline 15 & 85 & 1 & 62 & 1 & 60 & 0 \\
\hline 16 & 110 & 8 & 87 & 3 & 75 & 0 \\
\hline 17 & 78 & 3 & 77 & 3 & 70 & 3 \\
\hline 18 & 66 & 0 & 87 & 0 & 80 & 0 \\
\hline 19 & 67 & 0 & 50 & 0 & 68 & 0 \\
\hline 20 & 43 & 0 & 44 & 0 & 50 & 0 \\
\hline 21 & 60 & 0 & 63 & 0 & 67 & 0 \\
\hline 22 & 55 & 0 & 65 & 0 & 70 & 0 \\
\hline 23 & 42 & 0 & 44 & 0 & 34 & 0 \\
\hline 24 & 76 & 0 & 79 & 0 & 56 & 0 \\
\hline 25 & 69 & 0 & 71 & 0 & 67 & 0 \\
\hline 26 & 82 & 0 & 82 & 0 & 86 & 0 \\
\hline 27 & 63 & 0 & 79 & 0 & 65 & 0 \\
\hline 28 & 85 & 1 & 115 & 1 & 113 & 1 \\
\hline 29 & 65 & 0 & 50 & 0 & 57 & 0 \\
\hline 30 & 43 & 2 & 22 & 1 & 17 & 1 \\
\hline 31 & 23 & 0 & 10 & 0 & 26 & 0 \\
\hline
\end{tabular}

AM: aerobios mesófilos, CT: coliformed totales

Fuente: autores

Normatividad colombiana: para aerobios mesofilos: máximo $100 \mathrm{ufc} / 100 \mathrm{ml}$, para coliformes totales 0 ufc/ $100 \mathrm{ml}$, esto de acuerdo a la resolución 2115 de 2007:

Tabla 3

Resultados toma de muestra en grifos de restaurantes escolares, Mayo de 2015

\begin{tabular}{|c|c|c|c|c|c|c|}
\hline \multirow{3}{*}{$\#$} & \multicolumn{2}{|c|}{ Toma 1 } & \multicolumn{2}{c|}{ Toma 2 } & \multicolumn{2}{c|}{ Toma 3 } \\
\cline { 2 - 7 } & \multicolumn{3}{|c|}{ Grifos ufc/100 mI } \\
\cline { 2 - 7 } & AM & CT & AM & CT & AM & CT \\
\hline 31 & $\geq 100$ & 100 & 208 & 0 & 73 & 36 \\
\hline 32 & $\geq 100$ & 324 & 25 & 0 & 60 & 0 \\
\hline 34 & $\geq 100$ & 32 & 72 & 0 & 352 & 0 \\
\hline 35 & $\geq 100$ & 46 & 2 & 0 & NT & \\
\hline 36 & $\geq 100$ & 0 & 103 & 0 & 24 & 0 \\
\hline 37 & $\geq 100$ & 22 & $\geq 100$ & $\geq 100$ & $\geq 100$ & $\geq 100$ \\
\hline 38 & $\geq 100$ & $\geq 100$ & $\geq 100$ & $\geq 100$ & $\geq 100$ & 58 \\
\hline 39 & $\geq 100$ & 45 & $\geq 100$ & $\geq 100$ & $\geq 100$ & $\geq 100$ \\
\hline 40 & $\geq 100$ & $\geq 100$ & $\geq 100$ & $\geq 100$ & $\geq 100$ & $\geq 100$ \\
\hline
\end{tabular}

AM: aerobios mesófilos, CT: coliformed totales

Fuente: autores 
De acuerdo a la tabla 3 , para los 9 restaurantes escolares participantes, se hallaron en todos los aerobios mesofilos por encima de $100 \mathrm{ufc}$, teniendo en cuenta que la norma exige que sean máximo hasta 100, y hallando coliformes 8 de las 9 muestras analizadas. Es de aclarar que coliformes fecales no se hallaron en ninguna de las muestras analizadas

El agua se usa para producir, procesar y, bajo ciertas condiciones, almacenar los alimentos. El agua se usa como ingrediente en muchos alimentos procesados. Por tanto, la calidad del agua influye en gran medida en la calidad microbiana de los alimentos. Se ha registrado contaminación de los alimentos con bacterias, virus y parásitos patógenos provenientes del agua (Bibek Ray, Arun Bhunia 2010).

Por lo anterior, se decidió indagar respecto a la calidad en restaurantes de diferentes estratos de San José de Cúcuta, hallando que el $30 \%$ de los sitios permitieron la revisión de los tanques de almacenamiento, hallando en ellos, fallas como falta de aseguramiento de la tapa, acondicionamiento, y se indago sobre la limpieza y desinfección, a lo cual respondieron que contrataban una empresa especializada pero no contaban con los respectivos registros.

De acuerdo al estudio realizado por Corrales Lucia y otros en 2014, sobre la determinación de bacterias patógenas para el humano en aguas de riego, tuvo como un objetivo principal de gestión de la calidad del agua desde una perspectiva de salud es garantizar que los consumidores no estén expuestos a niveles de agentes patógenos que puedan causar enfermedades. Un requisito prioritario en la prevención y la protección de la salud pública es tener resultados confiables y rápidos. Al evaluar la presencia de $E$. coli se mide el riesgo de la contaminación microbiana en el agua potable, esto es crucial para obtener resultados confiables rápidamente y así tomar las medidas de saneamiento oportunas, de acuerdo a esto se relaciona con la presente investigación, que pretendió evaluar la calidad del agua de restaurantes de diferentes estratos, a fin de conocer el grado de cumplimiento frente a la normatividad colombiana, consignada en la resolución 2115 de 2007.

Arias, Rubio et al., en México (2014), en el estudio Niveles de contaminación del agua potable en la cabecera municipal de Ascención Chihuahua, México, hallaron que alrededor del $80 \%$ de las muestras de agua dieron positivo para CT y CF y se encontraron diferencias por estación, lo que se asemeja en esta investigación donde se hallaron coliformes totales en el $45 \%$ de los puntos muestreados, pero en el $100 \%$ de las muestras estuvieron exentas de coliformes fecales, lo que demuestra sin embargo el incumplimiento, ya que la presencia de coliformes totales pone en riesgo el consumo de la comunidad de agua con este tipo de bacterias.

Moya, Raquel et al., (2013), demostraron que las salmonelosis constituyen la primera causa de toxoinfecciones alimentarias o por consumo de agua insalubre en el mundo, habiéndose determinado que están implicados más de 2.000 serotipos, de los cuales el serotipo Salmonella enteritidis es el predominante (56,8\% de casos), seguido por el serotipo Typhimurium .Al mismo tiempo que se ha registrado los brotes de diarrea por bacterias entre ellas Salmonella, se ha investigado el efecto del cloro y sus derivados, con el propósito de determinar la cantidad que debe usarse sin ocasionar daños laterales a la salud; estas investigaciones han dado a conocer que $S$. enteritidis necesita del incremento en la concentración de $\mathrm{HClO}$ para ser eliminada en presencia de materia orgánica y que las buenas prácticas en la desinfección del agua y de los alimentos debe iniciarse en la producción y procesamiento habiéndose establecido las Normas para su regulación, de acuerdo a esto se enfatiza en la importancia de llevar a cabo como en esta investigación la búsqueda del cumplimiento de la normativa, pero también de la búsqueda de otros analitos que no se contemplan en la misma a fin de garantizar la calidad y seguridad al consumir agua en los restaurantes de Cúcuta, a través de las bebidas, o de las frutas y verduras lavadas con la misma principalmente. 


\section{CONCLUSIONES}

El estrato no es una variable influyente en la calidad y cuidado del agua en restaurantes de la ciudad de San José de Cúcuta, ya que en algunos restaurantes de estratos 5 y 6 se hallaron altos niveles de contaminación y en otros de estratos 1 y 2 , se hallaron en estricto cumplimento de la normativa, teniendo en cuenta que en Colombia, se tiene como parámetros lo estipulado en la resolución 2115 de 2007. Sin embargo, se halló que

\section{REFERENCIAS BIBLIOGRÁFICAS}

Arias, H. O. R., Terrazas, L. R. B., Barraza, E. B., Palma, G. N. A., \& Terán, R. A. S. (2015). Niveles de contaminación del agua potable en la cabecera municipal de Ascención, Chihuahua, México. Nova Scientia, 7(14), 178-201.

Bibek Ray, Arun Bhunia, Fundamentos de Microbiología de los Alimentos, cuarta edición, México, Mac Graw Hill, 2010.

Camacho Quiñonez, Livia Vannesa Jurado Calvo, Julio César. 2014. Estudio del nivel de servicio, en el área de alimentos y bebidas del terminal terrestre de Guayaquil, asociado con la satisfacción de los usuarios. Disponible en: http://repositorio.ucsg.edu.ec/bitstream/123456789/2764/1/TUCSG-PRE-ESP-AETH-204.pdf.

Carolina Montoya, Diana Loaiza, Camilo Cruz , Patricia Torres, Juan Carlos Escobar, Luís Germán Delgado. Propuesta metodológica para localización de estaciones de monitoreo de calidad de agua en redes de distribución utilizando sistemas de información geográfica. 2009. Rev. Fac. Ing. Univ. Antioquia N. ${ }^{\circ}$ 49. pp. 129-140.

Corrales Lucia, Ligia Sánchez, Fabián Escucha. Determinación de la presencia de bacterias patógenas para el humano en aguas de riego en la cuenca alta de la sabana de Bogotá; D.C. Colombia. 2014. Disponible en file://C:/Users/acer/Downloads/1042-1361-1-PB.pdf.

Héctor Osbaldo Rubio Arias, Lourdes Raquel Balderrama Terrazas, Eduviges Burrola Barraza, Guadalupe Nelson Aguilar Palma y Rubén Alfonso Saucedo Terán. Niveles de contaminación del agua potable en la cabecera municipal de Ascensión, Chihuahua, México. Revista Electrónica Nova el $40 \%$ de los sitios incumplen con la normativa, y por ende, con la seguridad e inocuidad ofrecida a clientes, turistas y visitantes de los diferentes restaurantes, indicando fallas posiblemente en el almacenamiento, la falta de mantenimiento quizás no solo en tanques de almacenamiento, sino también de redes, y en los grifos que llevan años sin un cambio, y que en algunos casos a simple vista se ve la acumulación de biopeliculas en ellos.

Scientia, No 14 Vol. 7 (2), 2015. ISSN 2007 - 0705. pp: 178201.

José de Jesús Alba, José Luis Ortega, Gerardo Álvarez, Maribel Cervantes, Estela Ruiz, Norma Urtiz, Aurora Martínez. Riesgos microbiológicos en agua de bebida: una revisión clínica. 2013. Revista Química Viva - Número 3, año 12, diciembre 2013. Página 1 a 19.

Ministerio de la Protección Social, Resolución 2115 de 2007, Por medio de la cual se señalan características, instrumentos básicos y frecuencias del sistema de control y vigilancia para la calidad del agua para consumo humano.

Ministerio de la protección social, Decreto 3075 de 1997, Artículo 8 del decreto $3075 \mathrm{El}$ agua que se utilice debe ser de calidad potable y cumplir con las normas vigentes establecidas por la reglamentación correspondiente del Ministerio de Salud.

Norma técnica colombiana microbiología (NTC 4458) de alimentos y de alimentos para animales método horizontal para el recuento de coliformes o Escherichia coli o ambos. técnica de recuento de colonias utilizando medios fluorogénicos o cromogénicos.online.2007.[consultado 09/09/2013]. Disponible en:

http://es.slideshare.net/nataliavelasquez01/ntc4458-rtocoliformes-y-e-coli.

Protocolo de Vigilancia en Salud Pública. ETA. Instituto Nacional de salud. Colombia. 2014

Raquel Moya-Egoavil, Pedro Alvarado-Salinas y Nelly VásquezValles. Supervivencia de Salmonella typhi y Salmonella enteritidis en agua potable de cuatro distritos de Trujillo (Perú). REBIOLEST 2013; 1(2): páginas 35 a 42. 